\title{
The influence of values in shared (medical) decision making
}

\author{
Bettina Baldt
}

Received: 7 February 2019 / Accepted: 18 September 2019 / Published online: 18 November 2019

(C) The Author(s) 2019

\begin{abstract}
Definition of the problem The Shared Decision Making model is becoming increasingly popular also in the German-speaking context, but it only considers values of patients to be relevant for medical decisions. Nevertheless, studies show that the values of physicians are also influential in medical decisions. Moreover, physicians are often unaware of this influence, which makes it impossible to control it.

Arguments The influence of both patients' and physicians' values is examined from an empirical and normative perspective. The review about the empirical data provides a necessary overview about the status quo, whereas I deduct rules for valueinfluenced behaviour in the decision making process in the normative approach. Therefore, different scenarios are taken into account to explore in which situations it is acceptable for physicians to let their values be part of the decision making process. The conscious use of values is only possible, when physicians are aware of their influence. To raise awareness, the best option would be to educate future physicians about it in their training. Therefore, this article provides a teaching concept for a unit that could be part of an ethics class for physicians in training. Furthermore, patient's rights and responsibilities in the decision making process are discussed.

Conclusion I conclude that it is necessary to take the influence of values (more) into account and include this knowledge into the training of physicians. Conclusively, recommendations for patients and physicians and their dealing with values in shared decision making processes are suggested.
\end{abstract}

Keywords Medical decision making - Shared decision making · Values · Patient autonomy

B. Baldt $(\square)$

Department of Systematic Theology and Ethics, University of Vienna,

Schenkenstraße 8-10, 1010 Vienna, Austria

E-Mail: bettina.baldt@univie.ac.at 


\section{Der Einfluss von Werten auf Shared (Medical) Decision-Making}

Zusammenfassung Das Shared Decision Making-Modell für medizinische Entscheidungen ist gut untersucht und Wissenschaftlerinnen und Wissenschaftler aus den Bereichen Medizin, Psychologie und Medizinethik sind sich mehrheitlich einig, dass in medizinischen Angelegenheiten Ärztinnen und Ärzte mit Patientinnen und Patienten gemeinsam entscheiden sollen. Dieses Modell sieht (unter anderem) vor, dass die Werte von Patientinnen und Patienten eruiert werden, damit eine medizinische Entscheidung getroffen werden kann, welche möglichst gut mit den Werten der Patientin bzw. des Patienten übereinstimmt. Die Werte von Ärztinnen und Ärzten finden keine Erwähnung im Shared Decision Making-Modell. Mehrere Studien haben jedoch gezeigt, dass auch die Werte von Ärztinnen und Ärzten einen Einfluss auf medizinische Entscheidungen haben. In diesem Artikel sollen daher die Werte von Patientinnen und Patienten sowie Ärztinnen und Ärzten in Bezug auf medizinische Entscheidungen genauer untersucht werden. Dies geschieht aus empirischer sowie normativer Perspektive. Empirische Studien sollen aufzeigen, wie und in welcher Form Werte einen Einfluss auf medizinische Entscheidungen nehmen, während die Sichtweise der Normativität ethische Aspekte beleuchten wird. Dabei werden auch verschiedene Möglichkeiten berücksichtigt, wie die Werte von Ärztinnen und Ärzten Einfluss auf medizinische Entscheidungen nehmen können und mögliche Probleme im Zusammenhang mit der Patientenautonomie aufgezeigt. Besonders schwierig gestaltet sich die Situation dadurch, dass vielen Ärztinnen und Ärzten dieser Einfluss offenbar nicht bewusst ist, was es unmöglich macht, ihn zu kontrollieren. Daher ist ein wichtiger erster Schritt für Ärztinnen und Ärzte die Bewusstmachung und Reflexion der eigenen Werte. Erst dann kann darüber nachgedacht werden, an welcher Stelle in medizinischen Entscheidungsprozessen die Werte von Ärztinnen und Ärzten eingebracht werden können bzw. dürfen und an welcher Stelle dies auf keinen Fall erfolgen sollte bzw. dürfte. Um zukünftige Ärztinnen und Ärzte bereits in der Ausbildung auf den Einfluss von Werten aufmerksam machen zu können, bietet dieser Artikel ein Lehrkonzept für eine Unterrichtseinheit zu dieser Thematik, welches beispielsweise im Rahmen einer Ethik-Lehrveranstaltung angewandt werden könnte. Darüber hinaus sollen aber nicht nur die Handlungsoptionen von Ärztinnen und Ärzten ausgelotet werden; es wird außerdem die Verantwortung von Patientinnen und Patienten in Entscheidungsprozessen diskutiert. Diese Untersuchung zeigt, dass Werte mehr Einfluss auf medizinische Entscheidungen haben, als ihnen bisher zugestanden wurde. Die Offenlegung der eigenen Werte ist notwendig, damit ihr Einfluss auch kontrolliert werden kann. Nur durch einen kontrollierten Umgang mit eigens reflektierten Werten kann sichergestellt werden, dass die Patientenautonomie gewahrt wird. Schlussendlich werden konkrete Empfehlungen für den Umgang mit Werten in medizinischen Entscheidungen gegeben.

Schlüsselwörter Medizinische Entscheidungen - Geteilte Entscheidungen · Werte · Patientenautonomie 


\section{Introduction}

Decision making is omnipresent in medicine, and countless completely different matters have to be decided every day. "Which examination is necessary?", "Shall other physicians be involved?", "Which is the best treatment?" and so on. Contemporary approaches, like the Shared Decision Making (SDM) model, request that physicians and patients decide together upon medical matters (Elwyn et al. 2000). Even though some authors pointed out the limits of SDM (Woolf 2001; Whitney 2003), in most cases the benefits outweigh the disadvantages: Satisfaction and investment in the outcome of both patient and physician increase (Drolet and White 2012) while patients also profit by gaining knowledge and having more confidence in the decision making process (Elwyn et al. 2012).

Légaré and Witteman (2013) defined three key elements that characterise SDM: Firstly, physician and patient have to recognise and acknowledge that a decisionmaking process is needed. Secondly, both have to be aware of relevant clinical indications. Thirdly, the patient's values have to be incorporated.

"A value is a higher-order concept having broad control over an individual's more specific attitudes" (Hogg and Vaughan 2013, p. 175 f.). Rokeach (1973) perceives values as intended goals and distinguishes between terminal values (e.g., uniqueness, relatedness) and instrumental values (e.g., quality of life, autonomy). In the context of SDM, patients' values are elicited (values clarification/elicitation techniques can be used) to help them make a decision in accordance with their values (Abhyankar et al. 2011). Therefore, the elicited values are expected to lead to a preference for a particular treatment option.

The consideration of (patients') values in the decision making process is a-compared to the history of medicine-relatively new development as the paternalistic/beneficence model was prevalent for more than 2000 years (Will 2011a). In this model of medical decision making, physicians decided what was best for their patients, and patients obeyed their more or less well-trusted physicians. It was not until unsettling ways of conducting research during World War II came to light that the paternalistic model gradually gave way to the informed consent model (Will 2011b). The idea of the informed consent model was to provide patients with relevant medical information to enable them to make an informed decision (Faden et al. 1986). Thereby, the responsibility for medical decisions was taken from the physicians and handed to the patients themselves. Again, physicians were not required to engage with their patients' views and values.

This specific task was only demanded when the SDM model became prevalent, because for the first time, two different-i.e. the physician's and the patient's—views and values had to be integrated to come to a shared decision. In the German-speaking region, for example, this development also changed the study of medicine in terms of the physician-patient relationship and brought more attention to the importance of physicians' conversation techniques (Medical University of Vienna 2018; German Medical Faculty Association 2015; University of Basel, Medical Faculty 2011).

So far, only patients' values received attention in the context of SDM (Légaré and Witteman 2013). In order to correct this deficiency, the article discusses values of both patients and physicians from an empirical and normative perspective and 
also presents a teaching concept to educate future physicians about this matter. Conclusively, resulting recommendations for patients and physicians regarding SDM processes are suggested. As decisions in cancer care are a well researched topic of SDM (Hawley and Jagsi 2015; Hopmans et al. 2015; Steffensen et al. 2018), examples in this article focus on this patient group and its results are not presumed to be directly applicable to other patient groups.

\section{Empirical Perspective}

\section{Patients}

A systematic meta-study based on 22 qualitative papers revealed three value categories that patients consider to be important (Bastemeijer et al. 2017): values related to the individual (I-patient), values regarding the physicians' behaviour (II-professional), and values related to the interaction between patients and physicians (III-interaction). Further, specific values could be identified, which are broadly assignable to these three realms but are also overlapping because they are interrelated. Seven key values were the result of the review: uniqueness and autonomy (I), compassion, professionalism, and responsiveness (II), and partnership and empowerment (III). These universal values indicate that patients wish to be viewed as unique and autonomous individuals, who are treated professionally with respect and compassion and can at least decide if they want to take part in the decisionmaking process (Bastemeijer et al. 2017).

Another study concerned with patients' values asked cancer patients what their relatives, friends, and physicians should know about them and what mattered most to them (Naik et al. 2016). For example, if the cancer recurred, what should others know about their treatment goals? The study supplied evidence for five health-related values: self-sufficiency, life enjoyment, connectedness and legacy, balancing quality and length of life, and engagement in care (Naik et al. 2016). These results show that patients have individual values, which they will voice when asked about them. It is the physician's responsibility to incorporate them into the SDM process (Légaré and Witteman 2013).

\section{Physicians}

As the following studies demonstrate, physicians also have their own values that affect their medical decisions. Van Kleffens et al. (2004) found that the amount of pressure physicians exert on cancer patients to persuade them to undergo a particular treatment depends on the treatment goal. If there is a curative treatment goal, physicians try harder to convince patients to go along with their recommended treatment, while they respect the patient's autonomy more when a non-curative treatment is refused. This is a clear indication of the influence of physicians' values-in this case "as long as a medical procedure could cure your disease you should at least try it" - on the medical decision making process. Another study, which highlights this influence, found that physicians are more reluctant to engage in SDM when 
the patient prefers a treatment that is not recommended by the clinical guidelines (Sanders et al. 2017).

Furthermore, Hermann et al. (2015) conducted a study with 637 physicians and asked them about their values using the Portrait Value Questionnaire Revised (Schwartz et al. 2012). They divided them into two groups: one group highly valued achievement, power-resource, face (security and power by maintaining one's public image and avoiding humiliation), and conformity to interpersonal standards. The other group scored high on the values of hedonism, conformity to rules, and universalism-concern. Results uncovered that the first group used different criteria depending on the riskiness of a certain situation (the higher the risk, the stricter the assessment standards). The second group disregarded the risk and evaluated all situations with the same standards. Despite the small number of studies in this field, their results are indicative, and suggest that physicians' values exert influence on medical decisions.

\section{Normative Perspective}

In this section, I will provide arguments for rules concerning value-influenced behaviour in the decision making process. This will be done for patients and physicians separately as they have different roles in this process. However, I will not evaluate or assess the goodness, appropriateness or quality of specific values in the decision making process.

\section{Patients}

While the influence of physicians' values has to be critically scrutinized (Wiesing 2017), the influence of patient's values on medical decisions is welcome, since it is crucial that the chosen option reflects the patient's values-especially in oncology, where different treatment schemata are available. Patients have the right to an autonomous decision (Faden et al. 1986). Birnbacher (2012), however, argues that this right does not include an obligation for the patient to make an autonomous decision and that it is not permissible to educate a patient towards autonomy, except if these conditions apply: Patient autonomy ensures a better decision and it is wanted by the patient. In SDM, patients should decide together with their physicians, because only patients themselves know which option is in accordance with their values. Hence, patient involvement would lead to a better decision. Therefore, I argue that it is vital that physicians inform patients about the importance of their values, so that they also want to decide. Naturally, one cannot force patients to reflect upon their values and take part in the decision making process, but physicians should make an effort to convince them of the benefits. When it comes to value-decisions, it is perfectly understandable that patients ask physicians for their expert view, but it should not substitute their own reflection. 


\section{Physicians}

In the SDM model and in recommendations on how to implement it in the medical practice, only the patient's values receive attention and should be elicited during the decision making process (Elwyn et al. 2012; Légaré and Witteman 2013). However, as shown above, the physician's values also exert influence on medical decisions and thus, ought to be taken into account in deliberations on SDM processes. The studies also showed that there are two ways in which physicians' values influence medical decisions:

1. Physicians preselect options influenced by their values.

2. Physicians influence patients during the decision making process because of their values.

In the first case, the physicians' values already influenced the options that the physician is going to present to the patient. This means that the patient does not get all viable options to choose from, which clearly constitutes a violation of the patient's right to an autonomous decision (Beauchamp and Childress 2009) and should therefore be avoided. This raises the question, how physicians can be prevented from letting their values influence their selection of treatment options. Hermann et al.'s (2015) study also showed that almost one-quarter of the physicians stated in the questionnaire that their values did not influence their medical decisions at all. Hence, they are not aware of the influence.

In psychology, numerous studies revealed that humans often do not decide rationally because they struggle with the perception, processing and memory of information (Kirchler 2011). Unknowingly, people, who have to make a decision, draw on heuristics, which are rules of thumb for decision making that only use limited information. These heuristics often lead to right decisions, but can also result in systematic misjudgements (Kahneman and Tversky 1973; Tversky and Kahneman 1974). The only way to avoid these kinds of misjudgements is to be aware of the processes that lead to them. In medicine, there is often no simple right-or-wrongsolution to a certain issue, which is why it is often hard to determine, if the decision making was somehow biased. Nevertheless, a comparison between using heuristics for "simple" right-or-wrong-decisions and being influenced by values in medical decisions can be drawn. Only the awareness of one's own values allows for actively controlling the extent to which different values are going to be a part of the decision making process, which is similar to being aware of heuristics and not relying on them to make a decision.

Therefore, I argue that these insights should also be part of the physicians' training to prevent them from exerting their values unreflecting in the decision making process. Ideally, the regular reflection of values becomes part of the physician's fundamental attitude. Another strategy for making physicians aware that they are sometimes biased by their values is to integrate this knowledge into an SDM training (where the education about how to elicit patients' values could be extended to physicians' values). Plenty of SDM-related trainings were developed in the last years to help physicians to apply SDM-promoting techniques more efficiently (Diouf et al. 2016). The only problem with this approach is that while these trainings do result 
in more SDM behaviour and significantly decrease paternalistic decision making (Sanders et al. 2017) they are, however, more likely to change behaviours than attitudes (Bombeke et al. 2012). Hence, I think the implementation of a value education would be more effective in the training of physicians when they are about to develop their attitude as physicians rather than trying to tell practising physicians what to do (or even what they do wrong).

In the second case, the physicians' values come into play after they proposed viable options to the patient. Thereby, a distinction has to be drawn between situations, in which the patient asked for a recommendation and in situations, where this was not the case. If the patient did not ask for a recommendation, the physician should not give one. Physicians are required to share information, which is medically relevant for the decision (Légaré and Witteman 2013); however, it is not part of their job to try to influence patients and tell them their views unsolicited.

Admittedly, patients often ask for the physician's opinion when confronted with medical decisions (Elstein et al. 2005), which raises the question if the physician should or should not offer recommendations in this case. Birnbacher (2012), on the one hand, argues that the autonomy of a decision depends on how independent it is from the influence of others. On the other hand, Dove et al. (2017, p. 162) state, "[...] autonomy is most useful as an ethical norm when we recognize that it does not mean simply being left alone to decide". Therefore, it seems reasonable to say that physicians should not leave the patient alone with the decision, but should instead help them with the decision making process, especially when they are explicitly asked for such help. Ideally, physicians decide with the patient and not for the patient while exerting as little influence as possible.

To respect patient autonomy, I argue that it is necessary that physicians, who make a personal recommendation, highlight that this is their personal opinion. A patient's decision will most likely always be influenced by a physician's recommendation, but for patients to be able to assess the situation accordingly, physicians have to differentiate between what is medically indicated and what is their personal advice. For example, if there are multiple therapies available, but there is one most likely to be successful, physicians clearly should recommend that therapy (medically indicated recommendation, e.g., "Studies have shown that in cases like yours, this therapy works best."). If there are multiple therapies with different advantages and disadvantages, but the physicians favour one, all therapies have to be presented as viable options. If in this case, nevertheless, a patient asks for a recommendation and the physician has a personal opinion about it, it can be shared but it has to be stated that this opinion is personal (personal recommendation, e.g., "In my experience, this treatment is the most tolerable one. But from an evidence based medicine point of view, they are all possible options for you to choose from."). Otherwise, the physician would not respect the patient's right to an autonomous decision. 


\section{Educational Perspective}

In order to demonstrate how these new insights can be implemented into the training of physicians, I present a concept for a teaching unit that could be part of an ethics class.

\section{General Introduction to Values}

All students shall think of (any kind of) values and write each of them onto a piece of paper. All values are then collected on a blackboard or flipchart and the students shall try to categorize them into terminal and instrumental values (Rokeach 1973). The values can also be grouped thematically. This exercise shall give the students an impression of the multitude of values.

\section{Reflection of Personal Values}

In a next step, each student shall pick five values that best represent his or her own believes and rank the values in terms of importance. When they are done with the ranking, they shall explain it to another student and vice versa. This exercise gives the students opportunity to get in touch and reflect their own values. They will also discover that it can be difficult to put one value above another if they are all important to them (which patients often have to do when deciding in a medical matter). Furthermore, the students will see that if others value the same things as them, the ranking can still be different.

\section{Values in Medical Decision Making}

The next exercise stipulates the discussion of example cases, favourably ones from the students' own experiences. If they do not have any practical experience it is also possible to provide own examples or fictional ones (see "Case example"). It is important that the case examples involve some kind of physician-patient-interaction and a medical decision.

\section{Case example}

A 70-year old cancer patient receives chemotherapy. Physician and patient agree upon evaluating the treatment after about two months. The evaluation shows that the chemotherapy successfully reduced the cancer cells. It is clear that once the patient stops with the chemotherapy, the cancer will recur. The physician assumes the patient will want to resume with the chemotherapy due to the already successful treatment. The patient did not tolerate the chemotherapy well. He is very weak and had to spend most days at home with nausea. He plans to spend the remaining time with his family and does not want to resume with the chemotherapy. The physician tells him that without the chemotherapy his life expectancy is rapidly decreasing and that he would recommend continuing with the chemotherapy. The patient decides against it. 
The students' assignment is now to discuss the case example(s) and identify values that become apparent on the patient's and physician's side. They shall also try to determine, which value was the decisive factor and if the decision was rather the patient's or the physician's. (This will not be possible in all cases).

Furthermore, the students shall reflect how they would have decided if they were in the patient's place. This exercise can be done in pairs or smaller groups and gives the students once more the chance to reflect their own values, especially concerning medical decisions.

Now it is time to provide the students with empirical evidence about physicians' values in medical decision making. The students shall discuss whether and why these results are problematic. The article at hand can be used as reading material in terms of a summary for empirical evidence and as basis for the discussion of normative aspects.

With these new insights, the students shall revisit the example cases from before and analyse them regarding misconduct of the physician. Together, they shall think about how the physician could have acted differently in accordance with the rules about values in decision making that were set before. This can be done in pairs or groups.

To illustrate that every decision making process is different, various case examples can be discussed (depending on the available time). Conclusively, it shall become apparent to the students that the reflection of their own values should be done in every decision making process to ensure being aware of them and not influencing the patient in an unethical way.

\section{Conclusion}

This article offers an overview about patients' and physicians' values in medical decision making. While the importance of patients' values in SDM is clearly articulated (Légaré und Witteman 2013), the influence of physicians' values was hardly addressed in this context, which is also shown by the few studies that dealt with physicians' values (Hermann et al. 2015; van Kleffens et al. 2004; Sanders et al. 2017). As shown above, the values of physicians have to be considered in medical decision making as they affect medical decisions as well.

While it is crucial that patients reflect on their values and incorporate them into the decision making process, physicians have to be more careful. They should not preselect options according to their values before presenting them to their patients and only give recommendations if patients ask for them. Further, they should differentiate between medically indicated recommendations and personal recommendations. This is only possible if physicians also reflect upon their values and do not mistake their own views as medical facts.

In the same way, patients should be aware of the benefits of taking part in medical decision making processes. To share the responsibility of making a medical decision means that the decision is actually made together (Elwyn et al. 2014). SDM-from both sides - should not be reduced to the patient being able to say yes or no to a certain treatment. At the same time, it is the physicians' responsibility to involve 
the patient into the decision making process and to help the patients elicit their values (Légaré und Witteman 2013).

Consequently, these three key elements turn out to be particularly relevant for patients and physicians in SDM processes regarding values: (I) self-reflecting one's own values, (II) knowing about the impact of values on medical decisions, and (III) staying within one's area of expertise (physicians) resp. only asking for recommendations, where medical matters are concerned (patients). It is crucial that physicians are educated about these key elements in their training, which could be done using the teaching concept provided in the article. Only if physicians are educated about this, they can, in further consequence, educate patients about it, too, and ensure a value-oriented, and shared decision making process.

Funding This paper is part of the FWF-project "Understanding medical decision making". Open access funding provided by Austrian Science Fund (FWF): P 29509-G24.

\section{Compliance with ethical guidelines}

Conflict of interest B. Baldt declares that she has no competing interests.

Ethical standards For this article no studies with human participants or animals were performed by the author. All studies performed were in accordance with the ethical standards indicated in each case.

Open Access This article is distributed under the terms of the Creative Commons Attribution 4.0 International License (http://creativecommons.org/licenses/by/4.0/), which permits unrestricted use, distribution, and reproduction in any medium, provided you give appropriate credit to the original author(s) and the source, provide a link to the Creative Commons license, and indicate if changes were made.

\section{References}

Abhyankar P, Bekker HL, Summers BA, Velikova G (2011) Why values elicitation techniques enable people to make informed decisions about cancer trial participation. Health Expect 14(Suppl 1):20-32. https://doi.org/10.1111/j.1369-7625.2010.00615.x

Bastemeijer CM, Voogt L, van Ewijk JP, Hazelzet JA (2017) What do patient values and preferences mean? A taxonomy based on a systematic review of qualitative papers. Patient Educ Couns 100:871-881. https://doi.org/10.1016/j.pec.2016.12.019

Beauchamp TL, Childress JF (2009) Principles of biomedical ethics. Oxford University Press, New York

Birnbacher D (2012) Vulnerabilität und Patientenautonomie - Anmerkungen aus medizinethischer Sicht. MedR 30:560-565. https://doi.org/10.1007/s00350-012-3223-1

Bombeke K, Symons L, Vermeire E, Debaene L, Schol S, de Winter B, van Royen P (2012) Patientcentredness from education to practice: The 'lived' impact of communication skills training. Med Teach 34:e338-48. https://doi.org/10.3109/0142159X.2012.670320

Diouf NT, Menear M, Robitaille H, Guérard GP, Légaré F (2016) Training health professionals in shared decision making: Update of an international environmental scan. Patient Educ Couns 99:1753-1758. https://doi.org/10.1016/j.pec.2016.06.008

Dove ES, Kelly SE, Lucivero F, Machirori M, Dheensa S, Prainsack B (2017) Beyond individualism: Is there a place for relational autonomy in clinical practice and research? Clin Ethics 12:150-165. https://doi.org/10.1177/1477750917704156

Drolet BC, White CL (2012) Selective paternalism. Virtual Mentor 14:582

Elstein AS, Chapman GB, Knight SJ (2005) Patients' values and clinical substituted judgments: The case of localized prostate cancer. Health Psychol 24:85-92. https://doi.org/10.1037/0278-6133.24.4.S85

Elwyn G, Edwards A, Kinnersley P, Grol R (2000) Shared decision making and the concept of equipoise: The competences of involving patients in healthcare choices. Br J Gen Pract 50:892-897 
Elwyn G, Frosch D, Thomson R, Joseph-Williams N, Lloyd A, Kinnersley P, Cording E, Tomson D, Dodd C, Rollnick S, Edwards A, Barry M (2012) Shared decision making: A model for clinical practice. J Gen Intern Med 27:1361-1367. https://doi.org/10.1007/s11606-012-2077-6

Elwyn G, Lloyd A, May C, van der Weijden T, Stiggelbout A, Edwards A, Frosch DL, Rapley T, Barr P, Walsh T, Grande SW, Montori V, Epstein R (2014) Collaborative deliberation: A model for patient care. Patient Educ Couns 97:158-164. https://doi.org/10.1016/j.pec.2014.07.027

Faden RR, King NMP, Beauchamp TL (1986) A history and theory of informed consent. Oxford University Press, New York

German Medical Faculty Association (2015) National competency-based learning-objective catalogue. www.nklm.de/files/nklm_final_2015-07-03.pdf. Accessed 19 June 2019

Hawley ST, Jagsi R (2015) Shared decision making in cancer care: Does one size fit all? JAMA Oncol 1:58-59. https://doi.org/10.1001/jamaoncol.2014.186

Hermann H, Trachsel M, Biller-Andorno N (2015) Physicians' personal values in determining medical decision-making capacity: A survey study. J Med Ethics 41:739-744. https://doi.org/10.1136/ medethics-2014-102263

Hogg MA, Vaughan GM (2013) Social psychology. Pearson Education, Harlow

Hopmans W, Damman OC, Senan S, Hartemink KJ, Smit EF, Timmermans DRM (2015) A patient perspective on shared decision making in stage I non-small cell lung cancer: A mixed methods study. Bmc Cancer 15:959. https://doi.org/10.1186/s12885-015-1974-6

Kahneman D, Tversky A (1973) On the psychology of prediction. Psychol Rev 80:237-251. https://doi. org/10.1037/h0034747

Kirchler E (2011) Wirtschaftspsychologie; Individuen, Gruppen, Märkte, Staat. Hogrefe, Göttingen

van Kleffens T, van Baarsen B, van Leeuwen E (2004) The medical practice of patient autonomy and cancer treatment refusals: A patients' and physicians' perspective. Soc Sci Med 58:2325-2336. https://doi. org/10.1016/j.socscimed.2003.08.027

Légaré F, Witteman HO (2013) Shared decision making: Examining key elements and barriers to adoption into routine clinical practice. Health Aff 32:276-284. https://doi.org/10.1377/hlthaff.2012.1078

Medical University of Vienna (2018) Curriculum for the study of human medicine N202 (consolidated version) for the academic year of 2017/18. https://www.meduniwien.ac.at/web/en/studierende/meinstudium/diplomstudium-humanmedizin/studienplan-studienplanfuehrer/. Accessed 19 June 2019

Naik AD, Martin LA, Moye J, Karel MJ (2016) Health values and treatment goals of older, multimorbid adults facing life-threatening illness. J Am Geriatr Soc 64:625-631. https://doi.org/10.1111/jgs.14027

Rokeach M (1973) The nature of human values. The Free Press, New York

Sanders ARJ, Bensing JM, Essed MA, Magnée T, de Wit NJ, Verhaak PFM (2017) Does training general practitioners result in more shared decision making during consultations? Patient Educ Couns 100:563-574. https://doi.org/10.1016/j.pec.2016.10.002

Schwartz SH, Cieciuch J, Vecchione M, Davidov E, Fischer R, Beierlein C, Ramos A, Verkasalo M, Lönnqvist J-E, Demirutku K (2012) Refining the theory of basic individual values. J Pers Soc Psychol 103:663

Steffensen KD, Vinter M, Crüger D, Dankl K, Coulter A, Stuart B, Berry LL (2018) Lessons in integrating shared decision-making into cancer care. J Oncol Pract 14:229-235. https://doi.org/10.1200/JOP.18. 00019

Tversky A, Kahneman D (1974) Judgment under uncertainty: Heuristics and biases. Science 185: 1124-1131. https://doi.org/10.1126/science.185.4157.1124

University of Basel, Medical Faculty (2011) Selfassessment study of medicine. https:/www.google.com/ url?sa=t\&rct=j\&q=\&esrc=s\&source=web\&cd=11\&ved=2ahUKEwj7qKaqzubkAhUIilwKHR68D8c QFjAKegQICRAC\&url=https\%3A\%2F\%2Fmedizinstudium.unibas.ch\%2Ffileadmin\%2Fuser_ upload\%2Fmedizin\%2FDokumente\%2FLehrkonzept\%2FBericht_Endfassung_Mai_11.pdf\&usg= AOvVaw3RAmSN4RataRX7mYrVc1H0. Accessed 19 June 2019

Whitney SN (2003) A new model of medical decisions: Exploring the limits of shared decision making. Med Decis Making 23:275-280. https://doi.org/10.1177/0272989X03256006

Wiesing U (2017) Indikation; Theoretische Grundlagen und Konsequenzen für die ärztliche Praxis. Kohlhammer, Stuttgart

Will JF (2011a) A brief historical and theoretical perspective on patient autonomy and medical decision making: Part I: The beneficence model. Chest 139:669-673. https://doi.org/10.1378/chest.10-2532

Will JF (2011b) A brief historical and theoretical perspective on patient autonomy and medical decision making: Part II: The autonomy model. Chest 139:1491-1497. https://doi.org/10.1378/chest.11-0516

Woolf SH (2001) The logic and limits of shared decision making. J Urol 166:244-245 